\title{
Caem as máscaras na quarentena Covid-19: reflexões freireanas a partir de Cartas a Cristina
}

\author{
The masks fall in the covid-I 9 quarantine: freirean reflections from \\ Cartas a Cristina

\section{Las máscaras se caen en la cuarentena Covid-I 9: reflexiones freireanas a cerca de Cartas a Cristina}

\author{
Valdete Gusberti Cortelini I \\ https://orcid.org/0000-000 I-5090-6191 \\ Geraldo Antônio da Rosa2 \\ https://orcid.org/0000-0002-II93-7910
}

\begin{abstract}
Resumo: A presente carta pedagógica, a partir de uma interlocução com o livro Cartas a Cristina, apresenta a memória de Paulo Freire, suas percepções sobre como se constituiu enquanto ser humano, desde a sua infância, construindo-se educador em uma constante reflexão entre a sua vida e a sua práxis. A leitura do livro e suas provocações são sempre atuais, por isso nos possibilitam pensar a educação em tempo de pandemia, com novos desafios, perspectivas e propósitos mais humanos. O livro Cartas a Cristina, em um primeiro momento, atende às solicitações de escrita feitas por Cristina, e em um segundo bloco, Freire continua falando de si, mas considerando também temas sugeridos em âmbito nacional e internacional.
\end{abstract}

Palavras-chave: Docência. Formação. Prática pedagógica. Isolamento social.

\begin{abstract}
This writing of the pedagogical letter, from an interlocution with the book "Cartas a Cristina" brings the memory of Paulo Freire, his perceptions about how he constituted himself as a human being, since his childhood, building himself as an educator in a constant reflection between his life and his praxis. The reading of the book and its provocations are always up to date, so they allow us to think about education in a time of pandemic, with new challenges, perspectives and purposes that are more human. The book "Cartas a Cristina", at first, responds to Cristina's requests for writing, and in a second part, Freire continues to talk about himself, but also considering themes suggested at national and international level.
\end{abstract}

Keywords: Teaching. Formation. Pedagogical practice. Social isolation.

\footnotetext{
I Doutoranda e Mestre em Educação pela Universidade de Caxias do Sul-UCS/RS. Professora em cargo de Coordenação Pedagógica na Rede Municipal de Ensino de Vista Alegre do Prata, RS. E-mail: valdetegusbertic@yahoo.com.br

2 Doutor em Teologia pela EST-RS. Pós-Doutor em Humanidades na Universidade Carlos III-Madri, Espanha. Professor do Programa de Pós-Graduação em Educação na Universidade de Caxias do Sul-UCS/RS. E-mail: garosa6@ucs.br
}

Olhar de professor, Ponta Grossa, v. 24, p. I-7, e-1556I.023, 2021.

Disponível em <https://revistas2.uepg.br/index.php/olhardeprofessor> 
Resumen: La presente carta pedagógica, a través de una interlocución con el libro Cartas a Cristina, trae el recuerdo de Paulo Freire, sus percepciones sobre cómo se constituyó como ser humano, desde su infancia, construyéndose educador en una constante reflexión entre su vida y su praxis. La lectura del libro y sus provocaciones están siempre al día, por lo que nos permite pensar en la educación en una época de pandemia, con nuevos retos, perspectivas y propósitos más humanos. El libro Cartas a Cristina, en un primer momento, responde a las solicitudes de escritura de Cristina, y en un segundo bloque, Freire sigue hablando de sí mismo, pero a través de temas sugeridos a nivel nacional e internacional.

Palabras-clave: Docencia. Formación. Práctica pedagógica. Aislamiento social.

\section{Considerações iniciais}

A leitura da obra Cartas a Cristina, de Paulo Freire, possibilita-nos pensar o cenário educacional que estamos vivendo neste período de pandemia e quarentena, projetando-se para a reflexão sobre como nos constituímos educadores, nessa nova história de vida que mudou o percurso das nossas rotinas, de nossas lutas, de nossos sonhos, neste momento de isolamento e distanciamento social como medida de prevenção contra o novo coronavírus - COVID-I 9.

Compreendemos, no momento da leitura das cartas, que os escritos de Freire nos mostram que retornar ao passado nos faz refletir e buscar o distanciamento entre o momento vivido e $\circ$ projetado, remetendo-nos a uma constante vigilância das concepções e das ações que sustentam nossos saberes. O exercício de passar pelo vivido e pelo construído consolida a ideia de que o ser humano é movido por desafios que lhe possibilitam tornar-se cada vez mais humano, neste momento em que nos deparamos com novos desafios educacionais diante da suspensão das aulas, em razão da pandemia da COVID-19. As escolhas que fazemos direcionam nossas ações para nos libertarmos de situações pelas quais nos encontramos aprisionados, ou reforçamos nossas estruturas de vida, que consolidam o sentir-se humanos e encorajados na busca do desconhecido.

Dessa forma, entendemos que o professor vai se formando ao longo da vida, na relação com diferentes conceitos, no contato com diferentes sujeitos, que contribuem para sua constituição profissional e humana. As reflexões a seguir desafiam o educador a aproximar a leitura das cartas com sua práxis pedagógica e de vida. A atualidade nos faz pensar além dos currículos e das metodologias de ensino, nos clama para uma educação engajada em práticas sociais que contemplem o sujeito na sua integridade humana.

\section{Cartas a Cristina: um diálogo com a atualidade educacional em tempos de pandemia}

Nessa dinâmica, em que a leitura nos faz refletir sobre a prática na formação de professores, Paulo Freire apresenta a primeira carta, na qual discute a importância do pensar, relacionando o "menino de ontem" ao "homem de hoje", e nos instiga, na segunda carta, a tencionar sobre simbologias que elegemos em nome de respaldo social. Ainda que, muitas vezes, critiquemos a classe dominante e denunciemos a violência de classes, reforçamos, através de nossas ações, o lugar onde cada sujeito 
deve estar. Uma atitude de vigilância nos faz planear sobre os saberes que sustentamos e os poderes que legitimamos, materializados em nossos discursos e em nossas práticas.

Hoje, mais do que nunca, precisamos pensar no valor da vida, de cada vida. Cada realidade educacional, neste período de COVID-19, organizou-se da forma possível para manter o vínculo entre a escola e os alunos. Nessa relação, constituímo-nos mais humanos quando conseguimos nos colocar no lugar do outro, entendendo realidades diferentes. Parece-nos que, fora da escola, conseguimos perceber individualidades que, no cotidiano escolar, podem ser evocadas, mas não compreendidas, nem respeitadas.

Essas cartas nos fazem pensar sobre o quanto lideranças e autoridades subjugam pensamentos de ódio e desrespeito ao ser humano, encontrando respaldo significativo para esses ideais na população. Fica o convite para refletirmos sobre qual a nossa posição nessa luta de classes, de ideias e sobre como sustentamos ou produzimos violências ocultas por meio de discursos pedagógicos que, muitas vezes, usamos como um controle invisível e manipulador para que nada se modifique ou fuja do controle.

$\mathrm{Na}$ terceira carta, o testemunho assume valor significativo, uma vez que Freire recorda medos da infância e a importância afetiva da família, com destaque à figura do pai. Entendemos que nossa prática pedagógica tem efeito quando é testemunhada e vai se construindo ao longo da história de cada educador que, na sua constituição docente, busca aproximar suas concepções de mundo, de conhecimento e de sujeito com a prática desenvolvida. Assim, na quarta carta, Freire retrata o silêncio como expressão de significado em uma das mudanças que a família realizou da cidade de Recife para a cidade de Jaboatão e, através da quinta carta, relembra sua juventude e as injustiças que seus pais viveram na busca pelo sustento da família, trazendo a recordação do piano e da gravata, que asseguravam a imagem de credibilidade diante da sociedade cruel, injusta e desumana. Essas cartas mostram as marcas do processo de tornar-se humano e fazem denúncias ao autoritarismo nas dimensões da sociedade, da política, da escola e da família.

Em tempos de pandemia, qual é o nosso testemunho enquanto docentes? Preocupamo-nos com confrontos político-partidários ou com a eficácia da ciência? Entendemo-nos abertos para o novo e dispostos a assumir um processo de mudança?

Fomos impulsionados, neste ano de 2020, para a prática do distanciamento social, e nela nos reinventarmos, pensarmos a realidade educacional de cada local e traçarmos a melhor estratégia dentro das possibilidades, para que o vínculo com a escola não fosse interrompido e pudéssemos avançar com o conhecimento, mais voltado para a capacidade de se colocar no lugar dos pais, das famílias, do que para se preparar para uma prova, um exame. Com a pandemia, emergiu a necessidade de nos humanizarmos, com o propósito de cuidarmos da vida e do outro. 
Caem as máscaras na quarentena Covid-19: reflexões freireanas a partir de Cartas a Cristina

Ficamos na dimensão da escola e nos questionamos sobre as injustiças e a desumanização que, ao longo de nossa formação docente, ajudamos a legitimar com o testemunho de ações que reforçam essas práticas desumanas. Com o passar dos anos, sujeitos oriundos dessa educação assumem posições de lideranças e de tomada de decisão na sociedade, de modo que essas práticas sejam reforçadas e aprovadas em nome de especulações financeiras e do lucro acima de tudo. Cogitamos, enquanto educadores, que essa prática tem sustentação na atualidade porque ela encontra nos oprimidos o apoio defensor dos opressores.

E assim prossegue com suas reflexões quando, em sua sexta carta, instiga-nos a pensar sobre - quanto o professor faz a diferença na vida de um aluno, reforçando a ideia de inferioridade, de incapacidade, ou despertando sonhos, desejos de buscar e de fazer descobertas. Faz relação com seu momento vivido, suas experiências, suas observações frente à sociedade e a importância de sua professora "Cecília", que disse a sua mãe que iria ensiná-lo a partir do que já sabia, para buscar o que ainda não conhecesse. Essa atitude da professora, já no tempo em que Freire estudava, colocava-o inserido no mundo, fazendo-o refletir sobre seu conhecimento e sua condição humana. Assim, na sétima carta, deixa transparecer sua participação no mundo dos "meninos conectivos", transitando nas diferentes classes sociais e convivendo com pessoas amáveis, dialógicas e também com indivíduos brutos. Revela fatos que estabelecem relação entre opressor e oprimido.

A atualidade nos coloca diante desta situação em que, mesmo distantes, pelos cuidados com a saúde, procuramos manter vínculos com os alunos por meio das atividades enviadas para casa, utilizando-nos dos grupos de WhatsApp, das aulas on-line em plataformas, da interação entre professores e alunos. O objetivo é, sim, fazer com que os alunos não se afastem do conhecimento, mas principalmente que estabeleçam relações de afeto e cuidado pela vida de cada um e de cada família. O desafio nos coloca diante dessas estratégias em uma sociedade que continua dividida em classes, convivendo com pessoas amáveis e brutas, com princípios de vida que oscilam da destruição à preservação, do controle à autonomia, da submissão à democracia. Então, precisamos refletir se, na relação entre educador e educando, é possível haver diálogo, construção do conhecimento e de investigação, ou se essa relação reforça a transmissão de conhecimentos e a submissão entre sujeitos.

No entanto, mesmo diante de práticas desumanas, na oitava carta, Freire nos traz, de modo muito intenso, o conceito de esperança. De acordo com o autor, a esperança é condição para que o diálogo aconteça, juntamente com amor e humildade. Atrevemo-nos a aproximar esse conceito ao de ser mais. Esperança de ser mais curiosos no conhecimento de si e do mundo, convictos na conquista da liberdade, na busca de humanização do mundo e desafiados pelo novo. $E$ assim também, na nona carta, Freire relata os últimos momentos de vida de seu pai, em um misto de entendimento de morte, dor e esperanças. A figura da mãe se apresenta como pilar de consolação.

Olhar de professor, Ponta Grossa, v. 24, p. I-7, e-I556I.023, 2021.

Disponível em <https://revistas2.uepg.br/index.php/olhardeprofessor> 
Aproximamos essas duas cartas ao momento que hoje vivemos e, trazendo a "mãe" como simbologia de direcionamento de vida e de esperança, apoiamo-nos e buscamos forças para entender que a vida é a maior riqueza que temos para defender, mesmo em meio a tantos sinais de morte. Muitas vezes, precisam morrer verdades, certezas, práticas de vida rotineiras, para que possamos, através de ações de solidariedade, da ajuda mútua, da ciência e do cuidado com a mãe natureza, renascer e perceber o que de fato tem valor em nossa vida.

E em meio à busca, à esperança, à dor e à opressão, Paulo Freire relata, na sua décima carta, a marca da importância que dedicava aos livros. Considerava fundamental sua presença como norte para a busca de questionamentos e de significados no exercício da docência, no constituir-se educador. Nessa perspectiva, na décima primeira carta, escreve sobre sua experiência no SESI, demonstrando análises de ordem política, pedagógica, de natureza ética, ideológica, histórica e sociológica. Traz a formação de professores e dos pais conduzida a partir das manifestações da prática dos professores e das necessidades dos pais. Menciona também a relação entre teoria e prática, apresentando, na décima segunda carta, alguns pressupostos que constituem o exercício da docência: educador e educando como sujeitos da prática, não anulando suas individualidades; relação de conhecimento e de aprendizagem; ausência de neutralidade na prática educativa; não há docência sem discência; diálogo na prática educativa como possibilidade de pensar, criar e inovar; e docência e pesquisa com relações de reciprocidade.

Fica claro que não agimos de forma neutra; nossos atos e nossos pensamentos são carregados de conceitos e saberes que se voltam ao valor da condição humana como "gente", ou como "máquina", como "vida" ou como "lucro". No processo de interação com o ser humano, podemos possibilitar o diálogo ou a autoridade. Podemos nos questionar: Que educação temos? Que educação queremos? Que sociedade temos? Que sociedade queremos? Qual a importância da ciência para as políticas públicas voltadas à preservação da vida? No período em que estamos vivendo, de isolamento social, essas perguntas são latentes e precisam estar presentes no redimensionamento de nossas ações e projeções futuras.

E assim, na décima terceira carta, apresenta a transição para um segundo bloco em que continua falando de si, mas aborda temas sugeridos em seminários, entrevistas, leituras de jornais e revistas dentro e fora do Brasil. Nessa nova fase, a décima quarta carta nos desafia a pensar se o cotidiano se faz presente na sala de aula de forma crítica, contribuindo para a construção do conceito de liberdade. A democracia se ensina através de nosso testemunho, e, no diálogo, apresenta-se como possibilidade de nos libertar de nossos preconceitos. Nesse sentido, a carta também nos faz pensar sobre nossos compromissos com a educação.

Olhar de professor, Ponta Grossa, v. 24, p. I-7, e-1556I.023, 2021. 
Caem as máscaras na quarentena Covid-19: reflexões freireanas a partir de Cartas a Cristina

$\mathrm{Na}$ décima terceira e décima quarta cartas, podemos projetar o período pós-pandemia. $\mathrm{O}$ processo que estamos vivendo nos coloca em uma posição de mudança e de reinvenção. Quando voltarmos às aulas presenciais, não seremos mais os mesmos, e muitas coisas não serão como eram antes. Esse momento servirá para que possamos crescer coletivamente, na solidariedade e na prática educativa. Nos questionaremos: o cotidiano escolar traz a realidade vivida de forma crítica e presente? Qual é o papel da educação? Para que estudamos?

E assim prossegue na sua décima quinta carta, destacando que o professor democrático vai se constituindo no processo de seu fazer pedagógico, mas para isso precisa de duas virtudes: coerência e humildade. É fundamental aproximar o que pensamos e fazemos, estando sempre vigilantes através da reflexão, para diminuir essa distância. Nesse movimento, Freire apresenta, na décima sexta carta, a importância de desenvolvermos a habilidade de escuta. Não apenas a escuta entre educador e educando, mas na observação, na escuta de si mesmo, na reflexão, no respeito pelo outro.

Finalizando seus escritos, na décima sétima carta, instiga-nos a assumir uma posição curiosa de busca, e a construir conhecimento através da indignação. Em sua última carta, ressalta a importância de acreditarmos que a mudança é possível por meio do avanço da consciência ingênua para a consciência crítica, lutando por políticas públicas justas que conduzam ativamente as pessoas contra qualquer tipo de violência e desumanização.

As três últimas cartas nos colocam no compromisso social de construirmos um mundo mais humano. $O$ que estamos vivendo e presenciando com o mundo em quarentena nos faz refletir e nos encaminha para práticas em que se aproximem o que se diz e o que se faz, desenvolvendo nossa habilidade de escuta e de respeito de si, do outro e do mundo que nos abriga. Esse período é de muita aprendizagem humana.

\section{Considerações finais}

A leitura da obra Cartas a Cristina, de Paulo Freire, é sempre atual porque seus escritos nos possibilitam pensar a formação docente independentemente da época em que vivemos. "Me arrisco a dizer[...] Gente Humana é processo" [...] (FREIRE, 20I5, p. 13).

Nessa reflexão, torna-se gritante a implementação de políticas públicas que de fato aproximem o que se diz, o que se aprova e o que se faz, legislações e práticas coerentes em que o ser humano possa constituir-se protagonista da sua própria história, em um processo social e cultural, em que nenhuma individualidade seja negada, mas respeitada, na luta por uma sociedade mais justa e democrática.

Diante dos inúmeros clamores da atualidade, este momento tornou-se ímpar no sentido da presença do professor na sociedade. Por outro lado, caem as máscaras das carências de políticas 
públicas em âmbito social e educacional. Enquanto caem máscaras das mazelas educacionais no decorrer da quarentena, esse artefato se torna de uso imprescindível para a nossa sobrevivência. Acreditamos que, diante da crise ética, política e econômica associada à pandemia da COVID-19, o pensamento freireano, hoje mais do que nunca, torna-se extremamente importante, uma vez que houve muitos retrocessos em termos de sociedade. Diante dessa crise, vale a pena reforçar que a vida é um imperativo ético, por isso é necessário pensar em processos emancipatórios, frente à opressão política, social e econômica.

Acreditamos que nosso compromisso deve estar além dos personalismos, direciona-se ao encontro da ética e da ciência: essa é a grande lição que recebemos e com a qual necessariamente precisamos comungar.

\section{Referências}

FREIRE, P.; FREIRE, A. M. A. Cartas a Cristina: reflexões sobre minha vida e minha práxis. São Paulo: Paz e Terra, 2015.

Recebido em: 27 de maio de 2020.

Versão corrigida recebida em: 26 de setembro de 2020.

Aceito em: 26 de setembro de 2020.

Publicado online em: 26 e março de 2021 . 